\title{
Gross negligence manslaughter and hindsight
}

Hong Kong Med J 2021;27:384

https://doi.org/10.12809/hkmj219766

To the Editor-We read with interest the recent Editorial on gross negligence manslaughter. ${ }^{1}$ The third defendant in "DR" was employed by a clinic. She intravenously administered to healthy clients processed cells originally harvested from the client. The deceased received infusion on 3 October 2012 and passed away on 10 October from multiorgan failure due to septic shock caused by Mycobacterium abscessus. The indictment provided, inter alia':

1. the therapy was experimental for cancer patients, with unproven or uncertain efficacy;

2. there was no scientifically proven benefit on healthy patients;

3. the preparation involved prolonged culturing of blood cells with risk of contamination.

Any intravenous infusion outside a research setting must either be a registered pharmaceutical product of good manufacturing practice standard or comply with stringent quality requirements of a national blood transfusion service. It is foreseeable by any medical practitioner that lack of assurance of sterility would result in microbial contamination. Consideration through hindsight is not involved.

The Rose case is distinguishable. ${ }^{3}$ An optometrist performed routine eye examination for a 7-year-old on 15 February 2012, without retinal examination, which would have revealed papilloedema. Five months later, the boy passed away suddenly. The Court of Appeal quashed the gross negligence manslaughter conviction, as the boy was asymptomatic "with no material pre-existing history" in February; the significance of retinal examination was only realised with hindsight. ${ }^{3}$ We respectfully submit that the DR decision was consistent with the established gross negligence manslaughter law, with no significant ambiguity. Medical practitioners managing patients in accordance with standard medical practices would unlikely face criminal sanction.

\section{Author contributions}

Both authors contributed to the drafting of the letter and critical revision for important intellectual content. Both authors approved the final version for publication and take responsibility for its accuracy and integrity.

\section{Conflicts of interest}

All authors have disclosed no conflicts of interest.

\section{Funding/support}

This letter received no specific grant from any funding agency in the public, commercial, or not-for-profit sectors.

${ }^{1} \mathrm{KY}$ Yuen, MB, BS, MD

2 Janice YC Lo *, MB, BS, FRCPA

${ }^{1}$ Department of Microbiology, Li Ka Shing Faculty of Medicine, The University of Hong Kong, Hong Kong

${ }^{2}$ Centre for Health Protection, Department of Health, Hong Kong SAR Government, Hong Kong

*Corresponding author: janicelo@dh.gov.hk

\section{References}

1. Leung GK. Medical manslaughter: the role of hindsight. Hong Kong Med J 2021;27:240-1.

2. HKSAR v Mak Wan Ling. HKCFI 3069; 2020. Available from: https://legalref.judiciary.hk/lrs/common/search/ search_result_detail_frame.jsp?DIS $=132426 \& Q$ Q $=\% 28 \mathrm{ma}$ k\%2Bwan\%2Bling\%29\&TP=RS. Accessed 23 Aug 2021.

3. Regina v Rose HM. EWCA Crim 1168; 2017. Available from: https://www.bailii.org/ew/cases/EWCA/Crim/2017/1168. html. Accessed 23 Aug 2021. 